\title{
Three-year follow-up of changes of cortical bone thickness after implantation of Endo- Exo-Prosthesis (EEP) for transfemoral amputees
}

Marcus Örgel ${ }^{1 *}$, Emmanouil Liodakis ${ }^{1}$, Pratya Jaratjitwilai ${ }^{2}$, Afif Harb ${ }^{1}$, Nils Wirries ${ }^{3}$, Mohamed Omar ${ }^{1}$, Christian Krettek ${ }^{1}$ and Horst-Heinrich Aschoff ${ }^{1}$

\begin{abstract}
Introduction: Transcutaneous Osseointegrated Prosthetic Systems (TOPS) offer a good alternative for patients who cannot be satisfactorily rehabilitated by conventional suspension sockets. The Endo-Exo-Prothesis (EEP, ESKA Orthopaedic Handels $\mathrm{GmbH}^{\circledast}$, Deutschland) is the most implanted TOPS in Germany. Previous studies have shown that cortical thickness increases after implantation of TOPS. The aim of this study is to determine changes of cortical thickness in relation to the time after implantation of the Endo-Fix-Stem.

Patients and methods: All transfemoral amputees treated by EEP from 2007 to 2013 were operated by the last author of this study. X-ray images of 4 follow-up intervals (postoperative, 3 months, 12 months, 3 years) were analyzed retrospectively. The femoral residuum was divided into 3 sections (proximal, middle, distal) with 2 measuring points in each section: medial and lateral. Cortical thickness was measured at these 6 points and compared at regular intervals using the Friedman test for non-parametric dependent variables.

Results: Thirty-seven patients with 40 implants were included. The average age was 52.2 years (30-79years). 83.7\% of the patients were male. No statistical significance could be shown for any of the measuring points of the femoral residual (proximal medial, proximal lateral, middle medial, middle lateral, distal medial, distal lateral) among the mean values of the cortical thickness at the different follow-up times ( $p>0.05$ for all measuring points). Cortical remodeling processes (> 1 millimeter $(\mathrm{mm})$ ) occurred in all implants despite a missing statistical significance. Hypertrophy could be confirmed for $42.5 \%$ and atrophy for $37.5 \%$. Twenty percent of the cases showed a parallel occurrence of both entities. Cortical changes greater than $5 \mathrm{~mm}$ were only observed at the distal end of the femur.

* Correspondence: Oergel.Marcus@mh-hannover.de

Each author confirms that all investigations were conducted in conformity with ethical principles of research.

${ }^{1}$ Trauma Department, Hannover Medical School (MHH), Carl-NeubergStraße, 130625 Hannover, Germany

Full list of author information is available at the end of the article

(C) The Author(s). 2020 Open Access This article is licensed under a Creative Commons Attribution 4.0 International License, which permits use, sharing, adaptation, distribution and reproduction in any medium or format, as long as you give appropriate credit to the original author(s) and the source, provide a link to the Creative Commons licence, and indicate if changes were made. The images or other third party material in this article are included in the article's Creative Commons licence, unless indicated otherwise in a credit line to the material. If material is not included in the article's Creative Commons licence and your intended use is not permitted by statutory regulation or exceeds the permitted use, you will need to obtain permission directly from the copyright holder. To view a copy of this licence, visit http://creativecommons.org/licenses/by/4.0/ The Creative Commons Public Domain Dedication waiver (http://creativecommons.org/publicdomain/zero/1.0/) applies to the data made available in this article, unless otherwise stated in a credit line to the data. 
(Continued from previous page)

Conclusion: Even if our results did not show any significant difference, it can be deduced that the osseointegration process leads to a remodeling of the bone structure, both in terms of increased bone formation and bone resorption. However, it has not yet been conclusively clarified which processes lead to hyper- or atrophy. The force transmission between prosthesis and bone and the facultative bacterial colonization of the stoma are still the main factors which may be responsible for the bone remodeling processes.

Keywords: Transfemoral amputee, Endo-Exo-Prosthesis, Osseointegration, Transcutaneous osseointegrated prosthetic system (TOPS)

\section{Introduction}

The rehabilitation of upper and lower limb amputees by transcutaneous osseointegrated prosthetic system (TOPS) has been used in Sweden since 1990 [1] and offers a good alternative for patients who cannot be satisfactorily rehabilitated by conventional suspension sockets [2-9]. Currently, there are a lot of different TOPS available on the market. The Endo-Exo-Prothesis (EEP, ESKA Orthopaedic Handels $\mathrm{GmbH}^{\ominus}$, Deutschland) is the TOPS which has been used most often in Germany since 1999. Approximately, 150 patients have been treated with EEP in Germany [7].

Implantation of an EEP is performed as a two-stage procedure in our hospital. At first, the Endo-Fix-Stem is implanted, and then-after an osseointegration period of approximately 6 weeks - a stoma is applied to connect the external module to the inner femoral stem (Fig. 1) $[3,4,6,10,11]$. The osseointegration process is of central importance for success of the procedure. Grundei developed a 1st and 2nd generation spongy metal surface for this reason $[12,13]$. The second generation represents the surface of the stem used today. This surface consists of tripods with a selectable construction height of $0.65-3 \mathrm{~mm}$. They allow bone ingrowth in a reproducible strong and spatially structured manner. In addition, the three-dimensional surface of the tripods ensures a better distribution of the forces acting on the implant in order to minimize any movements between implant and

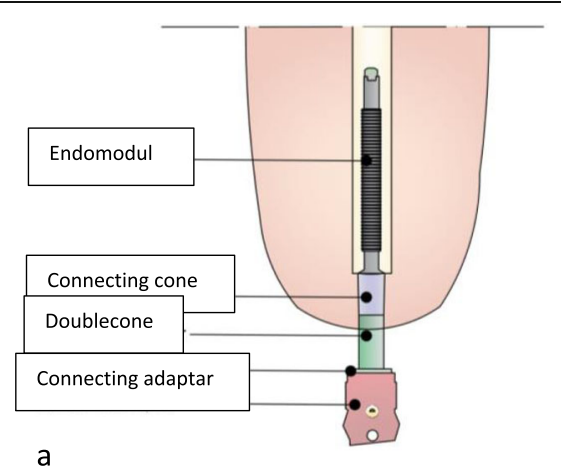

a

Proximal end of the prosthesis without osseointegrating function; possibility to attach a modular proximal femoral replacement;

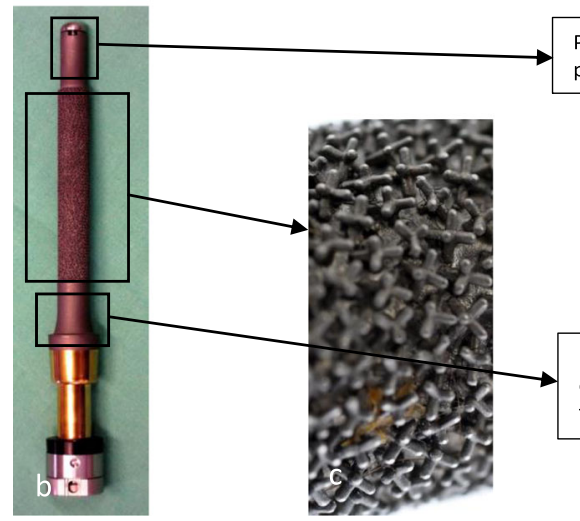

Distal implant area without tripod occupation, with conical distal design, which is aligned with the distal end of the femur as part of the implant placement

Fig. 1 a Schematic representation of the Endo-Exo-Prosthetic System. b Standard Endo-Fix-Stem with highlighted different areas of the prosthesis. $\mathbf{c}$ Enlargement of the implant surface of the tripods 
bone [13]. It is also intended to prevent any formation of soft tissue between implant and bone which has been associated with a higher risk of loosening and intramedullary ascending infections [13-16]. The use of EEP and the interaction between implant and bone lead to an increase in bone areas with higher load absorption, while the cortical structure is reduced in the bone areas which are under less pressure [17-20]. This implant-bone interaction is based on Julius Wolff's theories [17]. Previous studies have shown that cortical thickness increases after implantation of TOPS [21].

One of the most important aspects for the use of transcutaneous osseointegrated prosthetic systems (TOPS) is the osseointegration of the Endo-Fix-Stem (implant). The entire success of this system depends on the osseointegration. Therefore, the structural changes of the peri-implant bone are essential. The purpose of this retrospective study is to determine changes of cortical thickness in different areas of the femur residuum in relation to the time after implantation of the Endo-Fix Stem.

\section{Patients and methods}

This retrospective cohort study included all transfemoral amputees treated with EEP from 2007 to 2013. Exclusion criteria were death or implant loss. No patient had to be excluded. The amputees were examined for the clinicalradiological follow-up immediately after operation, 3 months, 12 months and 3 years postoperatively. A total of 37 patients ( 6 females and 31 males) with $40 \mathrm{im}$ planted Endo-Exo-Prosthesis were included. The patients were on average $52.2(30-79)$ years old. Digital xrays in the anterior posterior (a.p.) view were investigated with regard to cortical structural changes of the femur residuum after EEP treatment in four follow-up periods (see above). The $\mathrm{x}$-rays were imported and evaluated with the program-mediCAD (Version 3.50, mediCAD Hectec GmbH Opalstraße 54, 84032 Altdorf near Landshut, Germany). To detect bone changes in the femur, the femur was divided into three sections-a proximal, a middle, and a distal femoral third. After scaling the $\mathrm{x}$-rays, the cortical thickness was determined at the medial and lateral cortical bone, at these segments. The measurements were compared for all follow-up periods. All measurements were performed manually and were carried out once only.

$37.8 \%$ (14 prostheses) had an implant with a "flap" [4]. This is based on the implant design used until 2009 and partly prevented measurements in the distal femoral third (Fig. 2).

Continuous variables were presented as mean \pm standard deviation, while categorical variables were presented as absolute values and percentages (\%). Continuous variables were verified for normal distribution using the Shapiro-Wilk test. Differences for dependent, not

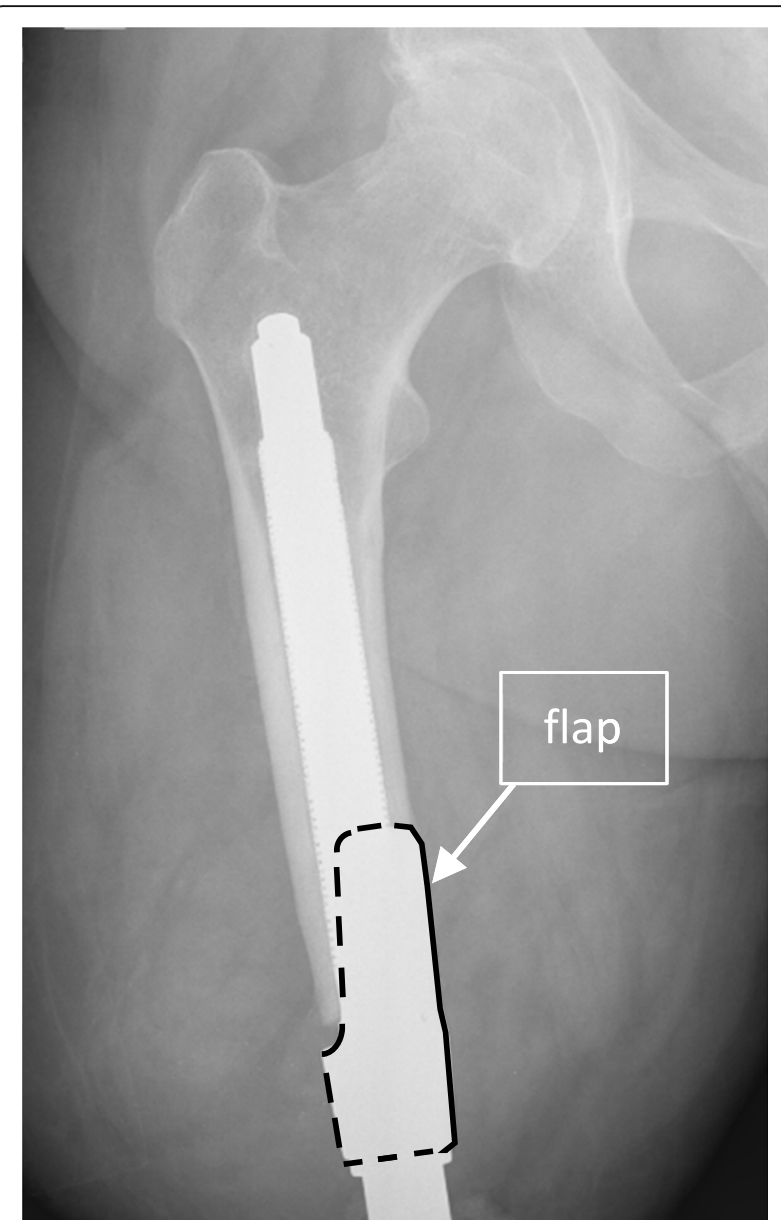

Fig. 2 Postoperative $x$-ray after implantation of an Endo-Fix-Stem. The flap, which was used for the older stems is framed with a dotted and continuous line in black. It was not possible to measure the corticalis thickness in this area

normally distributed continuous variables (corticalis thickness postoperatively, 3 months, 12 months, 3 years) were compared using the Friedman test, while categorical variables were compared using the Pearson chisquare test.

A two-tailed $p$ value of $\leq 0.05$ was considered to be statistically significant. The SPSS 23.0 program (SPSS Inc., Chicago, IL) was used for statistical analyses.

\section{Results}

The study included 37 patients with 40 implants. Patient demographics and implant characteristics can be found in Table 1. Three patients suffered from periprosthetic fractures (Fig. 3), which could be treated by open reduction and internal fixation with an angled plate. After 3 months, the patient could be mobilized in a standing and walking position. No further complications occurred during the follow-up periods. 
Table 1 Patient demographics and implant characteristics

\begin{tabular}{ll}
\hline Number of patients $(n)$ & 37 \\
\hline Number of implants $(n)$ & 40 \\
Age $(\varnothing)$ & 52.2 \\
(min.-max.) & $(30-79)$ \\
Prosthesis diameter in mm $(\varnothing)$ & 17 \\
(min.-max.) & $(14-20 \mathrm{~mm})$ \\
Prosthesis length in mm $(\varnothing)$ & 168 \\
(min.-max.) & $(140-180)$ \\
Implant side & \\
$\quad$ Right $(n)$ & 18 \\
$\quad$ Left $(n)$ & 22 \\
$\quad$ Bilateral $(n))$ & $(3)$ \\
Sex & \\
$\quad$ Male $(n)$ & 31 \\
Female $(n)$ & 6 \\
Prosthesis with a flap $(n)$ & 14 \\
\hline
\end{tabular}

Statistical mean values including standard deviation and $p$ values of the femoral cortical measurements are shown in Table 2. Continuous variables are presented with mean \pm standard deviation. In addition, the box plots of the measurements at the follow-up times are shown in Fig. 4.

All 40 implants (100\%) showed at least medial and/or lateral osseous structural changes $(>1 \mathrm{~mm})$ in one of the follow-up examinations. Fifteen implants (37.5\%) showed distal atrophy of the cortical bone, 17 implants (42.5\%) showed osseous hypertrophy (Fig. 5), and eight implants (20\%) showed both atrophy/traction and hypertrophy in the distal femoral third region.

A comparison of the cortical thickness between the postoperative and the three-year $\mathrm{x}$-ray control revealed a measurement difference of a hypertrophy of $>5 \mathrm{~mm}$ two times distal-medially and three times distal-laterally. In the middle (medial and lateral) and proximal (medial and lateral) measurement point, none of the cases showed a measurement difference of $>5 \mathrm{~mm}$. A measurement difference of $2-5 \mathrm{~mm}$ was observed six times distal-medially and seven times distal-laterally. A measurement difference of $2-5 \mathrm{~mm}$ occurred five times proximally medially and three times proximally laterally. These measurement results were recorded five times in the mid-medial and three times in the mid-lateral area. The measurement results were not statistically significant. The deviation of the case number at the time of the 3-year control $(n=30)$ from the total number $(n=$ 40) was due to the absence of the patients at the followup examinations or the use of the abovementioned flap.

\section{Discussion}

The results of our study showed hypertrophy and atrophy changes of the cortical bone in $100 \%$ of the investigated cases. These changes were not statistically

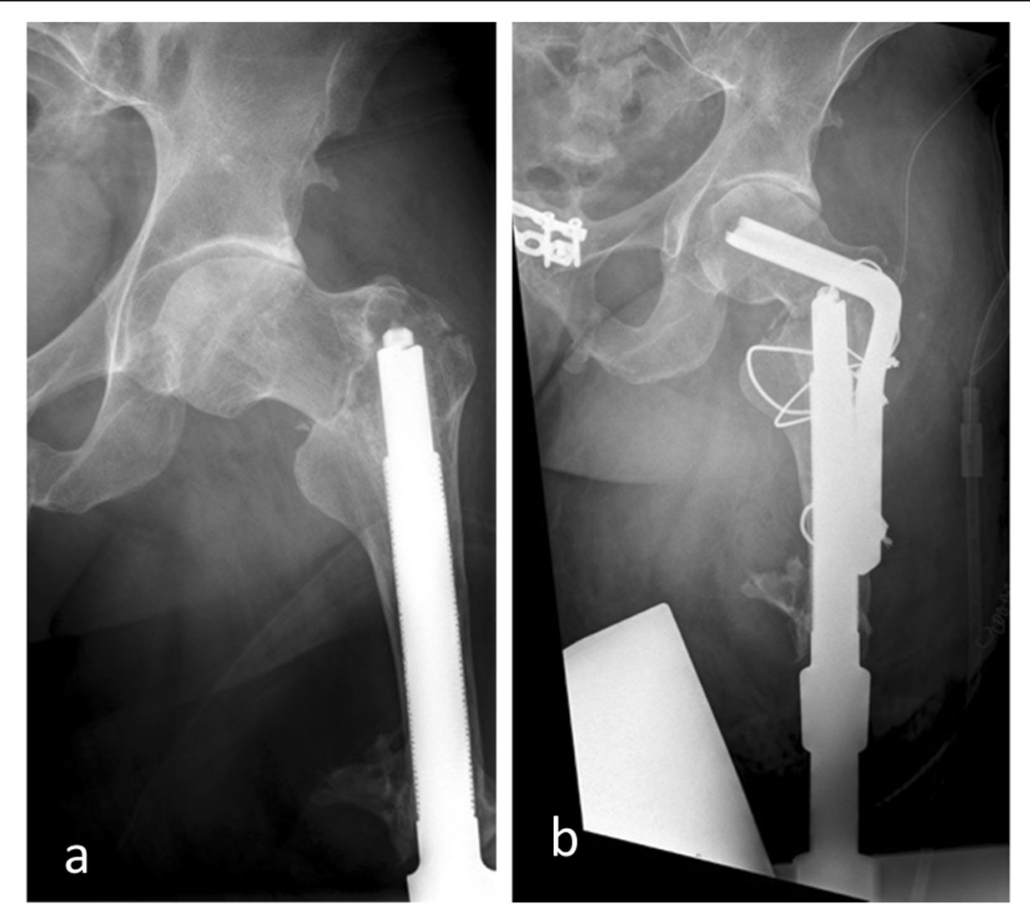

Fig. 3 a Periprosthetic fracture in left proximal femur after implantation of an Endo-Exo-Prosthesis. b Treatment with a $95^{\circ}$ angled blade plate 
Table 2 Mean femoral corticalis thicknesses ( \pm standard deviation) at the different follow-up periods

\begin{tabular}{|c|c|c|c|c|c|}
\hline Follow-up & Post-op $(n=40)$ & 3 Months $(n=40)$ & 12 Months $(n=37)$ & 3 Years $(n=30)$ & $p$ Wert \\
\hline Mean prox. medial in $\mathrm{mm}$ ( \pm standard deviation) & $6.92( \pm 3.27)$ & $7.16( \pm 3.22)$ & $6.54( \pm 3.51)$ & $4.59( \pm 3.41)$ & 0.692 \\
\hline Mean prox. lateral in $\mathrm{mm}$ ( \pm standard deviation) & $6.21( \pm 2.45)$ & $6.33( \pm 2.45)$ & $6.29( \pm 3.06)$ & $4.60( \pm 3.77)$ & 0.283 \\
\hline Mean middle medial in mm ( \pm standard deviation) & $6.31( \pm 3.55)$ & $6.45( \pm 3.18)$ & $6.21( \pm 3.35)$ & $4.28( \pm 3.11)$ & 0.745 \\
\hline Mean middle lateral in $\mathrm{mm}$ ( \pm standard deviation) & $6.42( \pm 2.16)$ & $6.52( \pm 1.59)$ & $6.47( \pm 2.01)$ & $4.42( \pm 3.18)$ & 0.105 \\
\hline Mean distal medial in $\mathrm{mm}$ ( \pm standard deviation) & $6.61( \pm 6.83)$ & $6.86( \pm 6.48)$ & $6.44( \pm 6.39)$ & $3.99( \pm 4.61)$ & 0.289 \\
\hline Mean distal lateral in mm ( \pm standard deviation) & $5.23( \pm 2.75)$ & $5.82( \pm 2.33)$ & $7.43( \pm 9.53)$ & $4.65( \pm 4.23)$ & 0.179 \\
\hline
\end{tabular}

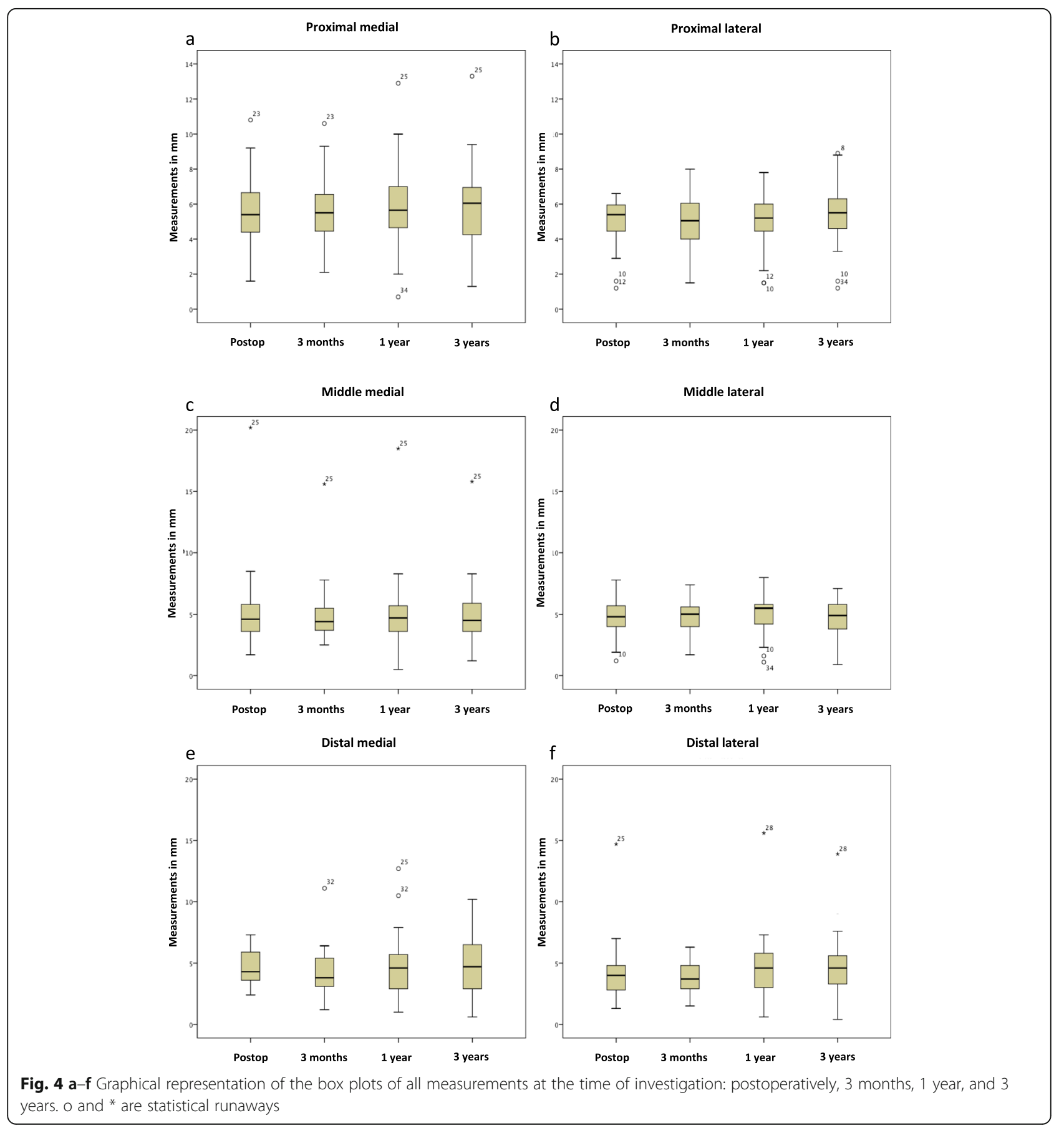




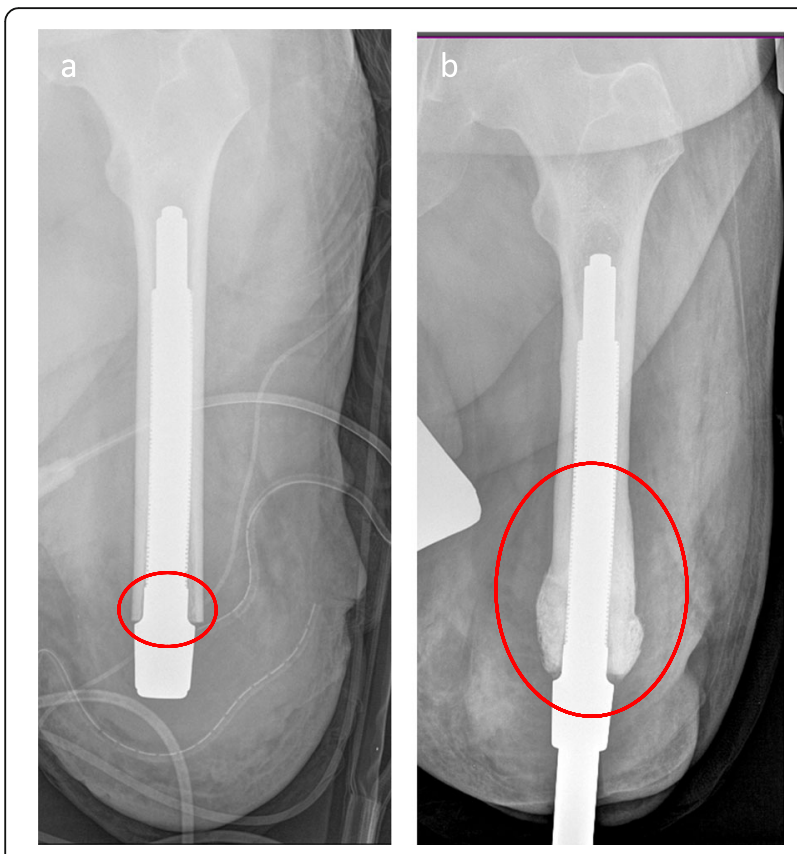

Fig. 5 a, b Postoperative $x$-ray after Endo-Exo-Prosthesis. The area marked with a red circle (small) depicts the bone-implant transition area that is not covered with tripods. $\mathbf{b}$ Example of osseous hypertrophy at distal end of femur in the 3-year follow-up including the implant transition area that is not covered with tripods (big red circle)

significant. This partly corresponds to the results of other studies about this topic performed with Osseointegrated Prostheses for Rehabilitation of Amputees (OPRA) and osseointegration prosthesis (OIP) [21-23].

If we compare our results with those from the working group of Haket et al [21], we find an increase in cortical thickness of $>5 \mathrm{~mm}$ in five measurements and an increase in cortical thickness between $2-5 \mathrm{~mm}$ in 21 measurements in the 3-year control group, but without statistical significance $(n=30)$. However, the working group in the Netherlands used the OIP. The measurement points were the same we used: proximal, in the middle, and distal. They were able to show a statistically significant increase of a maximum of $1.08 \mathrm{~mm}(p=0.021)$ (mean value 0.6 $\mathrm{mm}, p=0.020)$ in their 1-year check $(n=24)$ compared to the postoperative femoral cortical thickness, and of a maximum of $0.89 \mathrm{~mm}(p=0.007)$ (mean value $0.54 \mathrm{~mm}, p$ $<0.001)$ in their 2 -year check $(n=24)$ compared to the postoperative period [21]. In addition, they performed a bone density measurement of the femoral neck on both the amputated and contralateral side without any evidence of a significant change in bone density in their follow-up studies compared to the values measured prior to use of OIP [21]. The measurement points defined by Haket et al. were close to ours (Fig. 6). Our investigations showed also that the most noticeable bone remodeling processes took place in the distal femur region. This was also demonstrated by Nebergall et al. [23], who performed an examination of the OPRA system with a 6 -month $(n=$ 47), 1-year $(n=42), 2$-year $(n=40), 5$-year $(n=15)$, and 7 -year $(n=12)$ follow-up $(n=42)$. In line with our results, they showed that the most noticeable changes of the bone structure were visible at the distal end of the femur [23]. Similar results were presented by $\mathrm{Xu}$ et al. and Tomaszewski et al. in their studies, who conducted simulation trials for the OPRA system and for the OIP [22, 24].

Different theories can be considered for the most obvious changes in the distal femoral area, where the prosthesis leaves the bone tube. By adapting the design of the implant, the cylindrical and slightly curved shape was adjusted to the physiological curve of the femur (approximately $6^{\circ}$ curve). The intraoperative contour adaptation of the oval, intramedullary bone tube to that of the implant showed that the criteria for long-distance anchoring are to be preferred. Due to the high primary stability (press-fit anchoring) between implant and bone, which occurs during the first operation, the bone grows through the three dimensionally structured prosthesis surface (osseointegration) and creates a strong connection between bone and prosthesis. Nevertheless, an asymmetric implant abutment can be obtained in comparison with the three-point abutment of the press-fit anchoring of cementless hip joint endoprostheses, with a consecutive rise of the osseous structure in the areas where the prosthesis is anchored in the bone, and a reduction of the bone structure in the less heavily loaded areas. This effect is described in the implantation of cementless hip prostheses, along with the bone changes according to the stress-shielding in the Gruen Zones according to Wolff's law [17-20, 25-28]. If this theory is applied to the EEP, "fitting errors" could occur during the implantation of the Endo-Fix-Stem, and asymmetrical load distributions between bone and implant could occur at certain points on the intramedullary anchoring path of the prosthesis. According to Wolff's law and the conditions of stress shielding [20,26, 29,30], randomly placed, cortical changes along the entire press-fit anchorage length could occur.

Furthermore, the surgical technique may influence long-term changes in the femoral cortex. It requires rigid, conical drilling at the distal end of the residual bone immediately prior to implantation of the endo-fix stem $[4,10]$ (Fig. 7). This surgical step is necessary to adapt the femoral medullary canal to the shape of the implant (Fig. 1a). The reduced bone substance presumably leads to a reduction of the bone blood flow, which could further affect undisturbed osseointegration. In the absence of contact osteogenesis (tripod-free area of the implant) and partially thinned osseous structure, a progressive atrophy of the bone in this area can be detected $[31,32]$. On the other hand, excessive bone formation at 

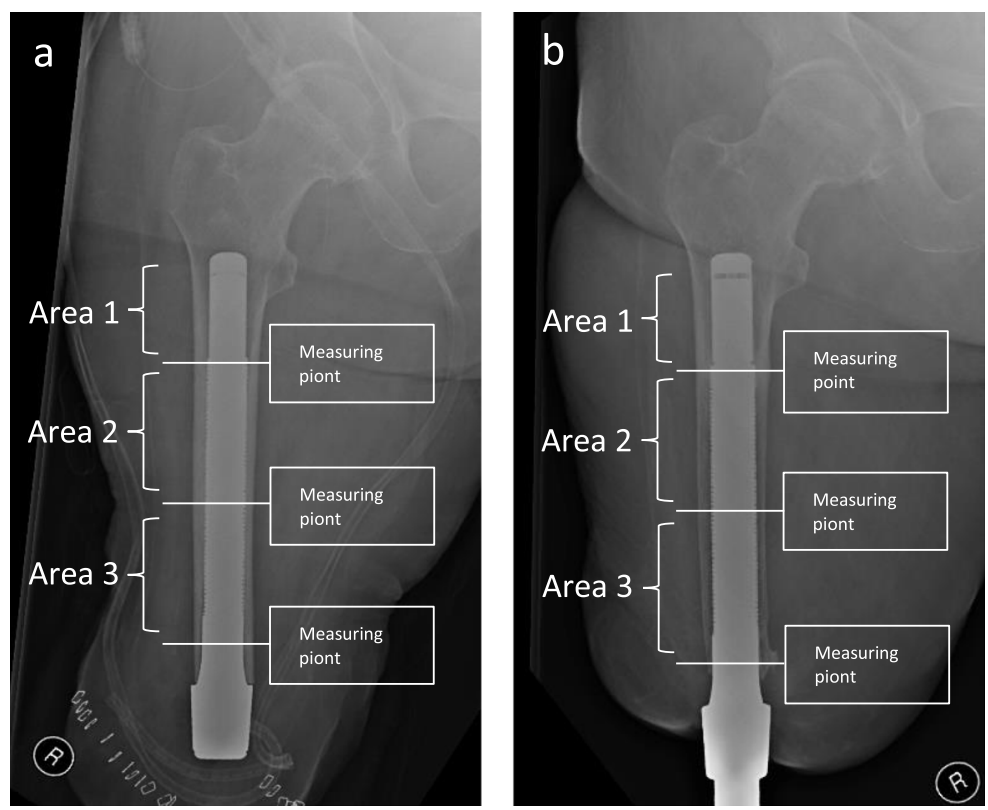

Fig. $\mathbf{6}$ a, b Postoperative x-ray after implantation of an Endo-Fix-Stem, right thigh, and residual femur; 3-year follow-up after stem implantation, with medial and lateral atrophy of the distal femur. Additionally, $\mathbf{a}$ and $\mathbf{b}$ show the division of the femur into three areas

the distal femur (Fig. 5) was also observed in patients who had undergone the same surgical technique. This could be the result of minimal vibrations of the implant at the distal implant-bone interface and, according to Wolff's law, could result in increased bone formation in this area by directly affecting the bone at the implantbone interface. A further cause for the distal osseous increase in the bone matrix could be the retention of small bone residues (drill meal), which become progressive in size and visible as heterotopic ossifications. In addition, some heterogeneous oscillations already exist preoperatively (Fig. 8) [33].

The three-dimensional tripod surface serves as an elastic intermediate layer and should enable smooth transition between the different elasticity modules of bone and implant $[15,34,35]$. In this way, the introduced forces at the implant-bone interface are split [13, $15,36,37]$ in order to reduce relative movements between implant and bone, so the formation of a tissue interface and ultimately an implant failure should be prevented [38, 39]. Nevertheless, chronic osteomyelitis can occur. The most severe form of this osteomyelitis, grade IV, describes a diffuse osteomyelitis involving the entire bone, which finally ends in bone necrosis [40]. Osteomyelitis is also classified histologically [41, 42]. A distinction is made between acute and chronic forms. Acute osteomyelitis is characterized by the detection of intramedullary neutrophil granulocytes with a clumped
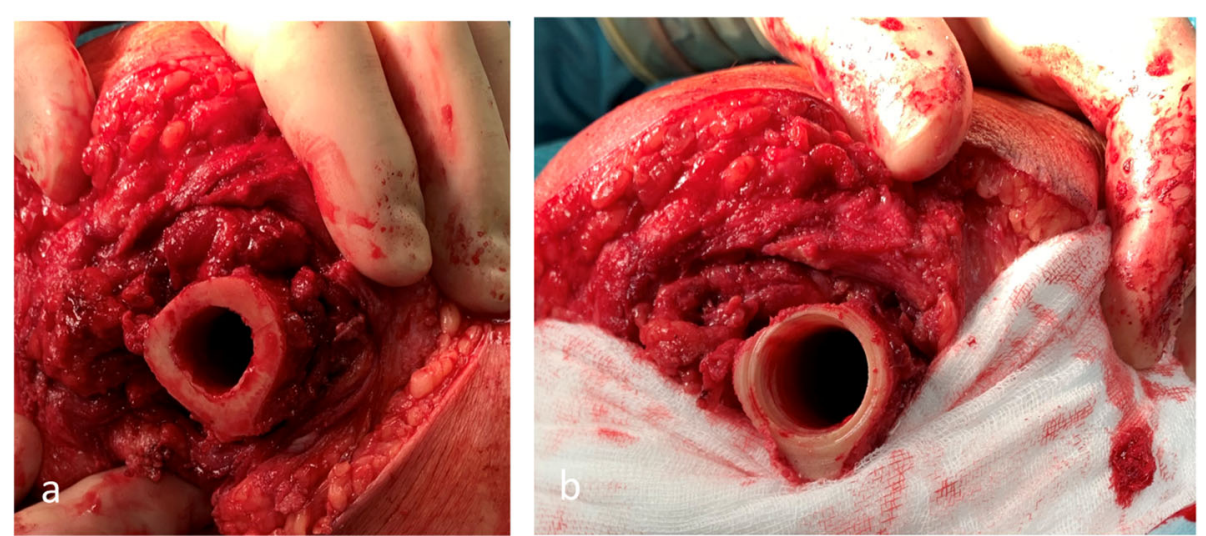

Fig. 7 a Illustration of the distal femur after flexible reaming. b After flexible reaming of the femur canal follows rigid reaming of the distal part of the femur which produces an asymmetrical cortex (ventral side thinner than dorsal) 


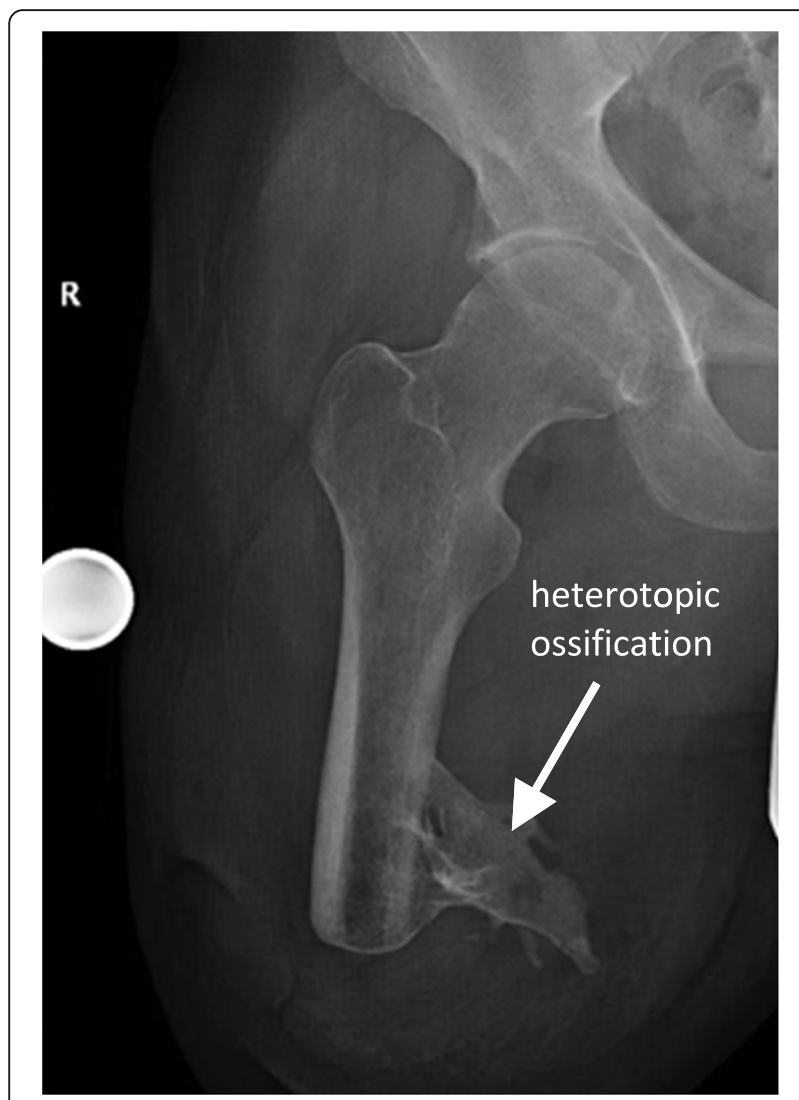

Fig. 8 Preoperative $x$-ray with a 30-mm reference ball to plan an EEP treatment. Large ossification depicted at the distal medial femur

chromatin structure as a sign of apoptosis and with optically empty osteocyte lacunae in the sense of bone necrosis [41, 42]. Chronic bacterial osteomyelitis is characterized histopathologically by spongy bone tissue with reactive bone formation and focal inflammatory bone resorption as well as by highly fibrosed medullary spaces with inflammatory infiltrate $[41,42]$. There is no corresponding study on the prosthesis system we use. However, it is conceivable that these aspects could be found in histological examinations of the bone from the distal femur. So, the bacterial colonization of the soft tissue stoma could also be responsible for the resorptive processes in the distal bone region [16].

Besides reducing the relative movements between implant and bone by the tripods to avoid a connective tissue interlayer, the approximation of the elasticity modules also serves to prevent aseptic implant loosening "(https://de. wikipedia.org/wiki/Elastizitätsmodul)". Go Yamako reported that by modifying the implant stiffness, approximating the elastic modulus of bone, bone resorption could be reduced. At the same time, this leads to increased stress at the bone implant interface, accompanied by reduced strength of the bone implant connection [25]. Another prospective study examining $\mathrm{CT}$ data sets of the femur after fitting a total hip replacement supported this finding [43].

Muscular atrophy as well as partially incomplete or missing muscle insertions also influences the processes of bone change. These processes lead to a reduced cortical bone structure due to the missing muscular insertions and ultimately to mineral reduced bone quality and subsequent atrophy $[8,44,45]$. This circumstance was not considered in this follow-up examination.

The laws established by Julius Wolff for the analysis of the interaction of bone and Endo-Fix-Stem are the central component on which the assumptions regarding cortical changes in the context of treatment with Endo-Exo-Prosthetics are based. Thus, atrophy at the distal end of the femur could most likely be explained by the missing load bearing at the distal implant-bone interface (area not covered by tripods) according to the stress shielding and osseous hypertrophy in the same area by an increased load transfer between prosthesis and bone, presumably caused by vibrations or possibly by a randomly high press-fit anchorage in this area, according to Wollf's law [13].

There are several limitations to this study. First, although all patients were supposed to come to all predefined follow-up appointments, some patients missed one or more of the scheduled appointments (Table 2). Second, the use of the flap until $2009(n=14)$ made distal measurements problematic. Depending on the intraoperative positioning of the flap, this could cover areas either distal-medial or distal-lateral in the a.p. $x$-ray.

Third, the rotation of the femur while performing $x$ rays may have influenced the measurements of the cortical thickness. It is known that even small degree deviations in the rotation of the thigh can lead to different cortical thickness due to the asymmetrical form of the femur. Lastly, the weight bearing status of the patients has not been clearly documented in the charts. There could be a correlation between the weight bearing status and the osseous change processes.

Despite all abovementioned limitations, this is, to our best knowledge, the first study measuring changes of cortical thickness in transfemoral amputees treated with EEP. In addition, our study presents the longest followup data for patients treated with this implant.

\section{Conclusion}

Based on these investigations and their critical assessment, both bone formation, bone resorption, and growth processes can be observed. The weight transmission between implant and bone, the surface structure of the implant, the amputation level as well as the muscle pull from the outside onto the bone, and the surgical technique, as well as the bacterial colonization, are relevant for the bony changes. Even though our results did not show any significant difference with regard to cortical 
changes in the load-bearing, diaphyseal region of the bone, we assume, as already shown by other authors (see above), there will be a consecutive increase in cortical bone mass in areas with increased force transmission between bone and prosthesis, and that bone resorption will occur in areas that are not amenable to direct force transmission at the bone-implant interface.

It has not yet been conclusively clarified in detail which process (force transmission, obligatory bacterial colonization, surgical technique, axle load, etc.) leads to hyper- or atrophy. However, the laws established by Julius Wolff and the stress shielding caused by the change from pressure to pull are the central components in the analysis of the interaction of bone and endo-fix stem. They are based on assumptions regarding cortical changes within the framework of the treatment with endo-exo prosthetics and ensure long-term success with sufficient press-fit anchorage. However, further scientific questions have to be investigated.

A lifetime of more than 15 years, accompanied by a high level of patient satisfaction compared to socket wearers, shows that the care concept using transcutaneously derived, osseointegrated prosthesis systems (TOPS) for transfemoral amputees represents a good treatment alternative.

\section{Abbreviations}

TOPS: Transcutaneous osseointegrated prosthetic systems; EEP: Endo-exo prosthesis; mm: Millimeter; a.p.: Anterior posterior; OPRA: Osseointegrated Prostheses for Rehabilitation of Amputees; OIP: Osseointegration prosthesis; $p$ : $P$ value; E. g.: Exempli gratia; $n$ : Number of patients

\section{Acknowledgements}

All listed authors have approved the manuscript before submission, including the names and order of authors, and that all authors receive the submission and all substantive correspondence with editors, as well as the full reviews, verifying that all data, figures, materials, and code, even those developed or provided by other authors, comply with the transparency and reproducibility standards of the journal and within the field.

\section{Institutional Review Board Approval (IRB Approval)}

An IRB Approval is not required because the investigators conducting this research obtained (1) no data through intervention or interaction and (2) no identifiable private information.

\section{Authors' contributions \\ ÖM: Idea of this work, ethic committee approval, writing the paper, and measurement. LE: Contributor to the review process and statistical analysis. JP: Contributor to the measurement. HA: Contributor to the review process and interpretation of the results. WN: Contributor to the discussion. OM: Contributor to the statistical analysis. $\mathrm{KC}$ : Contributor to the review. $\mathrm{AHH}$ : Contributor to the introduction. The authors read and approved the final manuscript.}

\section{Funding}

Not applicable for that section.

\section{Availability of data and materials}

The data sets generated and/or analyzed during the current study are available at Hannover Medical School repository at the trauma department.

Ethics approval and consent to participate

The ethics committee had no objections.
Consent for publication

Not applicable for that section.

\section{Competing interests}

Each author certifies that he has no commercial associations (e.g., consultancies, stock ownership, equity interest, and patent/ licensing arrangements) that might pose a conflict of interest in connection with the submitted article. All authors declare that they have no competing interests.

\section{Author details}

${ }^{1}$ Trauma Department, Hannover Medical School (MHH), Carl-NeubergStraße, 130625 Hannover, Germany. ${ }^{2}$ Bangkok Hospital Pattaya, Banglamung, Chonburi, Thailand. ${ }^{3}$ Orthopaedic Department, DiakovereAnnastift, Hannover, Germany.

Received: 16 January 2020 Accepted: 6 April 2020

Published online: 04 May 2020

\section{References}

1. Branemark R, Branemark PI, Rydevik B, Myers RR. Osseointegration in skeletal reconstruction and rehabilitation: a review. J Rehabil Res Dev. 2001;38:17581.

2. Willy C, Krettek C. [Transcutaneous osseointegrated prosthesis (TOP) after limb amputation : Status quo and perspectives]. Transkutane osseointegrierte Prothesensysteme (TOPS) nach Extremitatenamputation : status quo und Ausblick. Unfallchirurg. 2017;120:395-402.

3. Staubach, K.-H., Grundei, H. \& Aschoff, H. Endo-/exoprothese. in Ossäre Integration 190-194 (Springer Berlin Heidelberg, Berlin, Heidelberg, 2006).

4. Aschoff HH, Clausen A, Hoffmeister T. The endo-exo femur prosthesis--a new concept of bone-guided, prosthetic rehabilitation following aboveknee amputation. Z Orthop Unfall. 2009;147:610-5.

5. Aschoff HH, Juhnke DL. [Endo-exo prostheses: Osseointegrated percutaneously channeled implants for rehabilitation after limb amputation]. Endo-Exo-Prothesen : Osseointegrierte, perkutan ausgeleitete Implantate zur Rehabilitation nach GliedmaSSenamputation. Unfallchirurg. 2016:119:421-7.

6. Juhnke DL, Aschoff HH. Endo-exo prostheses following limb-amputation. Orthopade. 2015:44:419-25.

7. Aschoff $\mathrm{HH}$. Transcutaneous osseointegration after limb amputation : a review over 27 years. Unfallchirurg. 2017;120:278-84.

8. Ducher G, Bass SL, Saxon L, Daly RM. Effects of repetitive loading on the growth-induced changes in bone mass and cortical bone geometry: a 12month study in pre/peri- and postmenarcheal tennis players. J Bone Miner Res. 2011;26:1321-9.

9. Al Muderis M, Lu W, Li JJ. Osseointegrated prosthetic Limb for the treatment of lower limb amputations : experience and outcomes. Unfallchirurg. 2017;120:306-11.

10. Aschoff $\mathrm{HH}$, Juhnke DL. Evaluation of 10 years experience with endo-exo femur prostheses - background, data and results. Z Orthop Unfall. 2012;150:607-14.

11. Juhnke DL, Beck JP, Jeyapalina S, Aschoff HH. Fifteen years of experience with integral-leg-prosthesis: cohort study of artificial limb attachment system. J Rehabil Res Dev. 2015;52:407-20.

12. Mittelmeier W, Grunwald I, Schafer R, Grundei H, Gradinger R. Cementless fixation of the endoprosthesis using trabecular, 3-dimensional interconnected surface structures. Orthopade. 1997:26:117-24.

13. Gradinger, R. \& Gollwitzer, H. Ossäre Integration, (Springer-Verlag Berlin Heidelberg, 2006).

14. Pilliar, R.M., Lee, J.M. \& Maniatopoulos, C. Observations on the effect of movement on bone ingrowth into porous-surfaced implants. Clin Orthop Relat Res, 108-113 (1986).

15. Henrici, M. Doktorarbeit, Technischen Universität München Klinikum rechts der Isar (2006).

16. Lenneras $\mathrm{M}$, et al. The clinical, radiological, microbiological, and molecular profile of the skin-penetration site of transfemoral amputees treated with bone-anchored prostheses. J Biomed Mater Res A. 2017;105:578-89.

17. Wolf JH. Julis Wolff and his "law of bone remodeling". Orthopade. 1995;24:378-86.

18. Lerch $\mathrm{M}$, et al. Bone remodeling after total hip arthroplasty with a short stemmed metaphyseal loading implant: finite element analysis validated by a prospective DEXA investigation. J Orthop Res. 2012;30:1822-9. 
19. Lerch $M$, et al. Bone remodelling around the Metha short stem in total hip arthroplasty: a prospective dual-energy X-ray absorptiometry study. Int Orthop. 2012;36:533-8.

20. Engh CA, Bobyn JD, Glassman AH. Porous-coated hip replacement. The factors governing bone ingrowth, stress shielding, and clinical results. J Bone Joint Surg (Br). 1987;69:45-55.

21. Haket LM, Frolke JPM, Verdonschot N, Tomaszewski PK, van de Meent H. Periprosthetic cortical bone remodeling in patients with an osseointegrated leg prosthesis. J Orthop Res. 2017;35:1237-41.

22. Xu W, Robinson K. X-ray image review of the bone remodeling around an osseointegrated trans-femoral implant and a finite element simulation case study. Ann Biomed Eng. 2008:36:435-43.

23. Nebergall A, et al. Stable fixation of an osseointegated implant system for above-the-knee amputees: titel RSA and radiographic evaluation of migration and bone remodeling in 55 cases. Acta Orthop. 2012;83:121-8.

24. Tomaszewski PK, Verdonschot N, Bulstra SK, Rietman JS, Verkerke GJ. Simulated bone remodeling around two types of osseointegrated implants for direct fixation of upper-leg prostheses. J Mech Behav Biomed Mater. 2012;15:167-75.

25. Yamako $\mathrm{G}$, et al. Improving stress shielding following total hip arthroplasty by using a femoral stem made of beta type Ti-33.6Nb-4Sn with a Young's modulus gradation. J Biomech. 2017;63:135-43.

26. Engh, C.A. \& Bobyn, J.D. The influence of stem size and extent of porous coating on femoral bone resorption after primary cementless hip arthroplasty. Clin Orthop Relat Res, 7-28 (1988).

27. Yan SG, et al. Periprosthetic bone remodelling of short-stem total hip arthroplasty: a systematic review. Int Orthop. 2018;42:2077-86.

28. Lerch $M$, et al. Numeric simulation of bone remodelling patterns after implantation of a cementless straight stem. Int Orthop. 2013;37:2351-6.

29. Huiskes R. Stress analyses of implanted orthopaedic joint prostheses for optimal design and fixation. Acta Orthop Belg. 1980;46:711-27.

30. Huiskes R. Some fundamental aspects of human joint replacement. analyses of stresses and heat conduction in bone-prosthesis structures. Acta Orthop Scand Suppl. 1980;185:1-208

31. Osborn JF. Biological behavior of the hydroxyapatite ceramic coating on the femur shaft of a titanium endoprosthesis--initial histologic evaluation of a human explant. Biomed Tech (Berl). 1987;32:177-83.

32. Osborn, J.F. [Hydroxylapatite ceramic-granulate and its systematics]. Zahnarztl Mitt 77, 840-842, 844-848, 850-842 (1987).

33. Edwards DS, Kuhn KM, Potter BK, Forsberg JA. Heterotopic ossification: a review of current understanding, treatment, and future. J Orthop Trauma. 2016;30(Suppl 3):S27-30.

34. Farazin A, et al. A polycaprolactone bio-nanocomposite bone substitute fabricated for femoral fracture approaches: molecular dynamic and micromechanical investigation. Journal of Nanoanalysis. 2019.

35. Marjan Monshi, S.E., Amin Kolooshani, Bahareh Kamyab Moghadas, Saeed Saber-Samandari, Amirsalar Khandan. A novel three-dimensional printing of electroconductive scaffolds for bone cancer therapy application. Nanomedicine Journal (2020)

36. Aschoff, H.-H. TOPS - transkutane osseointegrierte prothesensysteme. Orthopädie und Unfallchirurgie up2date 12 (01), 87 - 105 (2017).

37. Esmaeili $\mathrm{S}$, et al. A porous polymeric-hydroxyapatite scaffold used for femur fractures treatment: fabrication, analysis, and simulation. Eur J Orthop Surg Traumatol. 2020;30:123-31.

38. Matsui $M$, et al. The metal-cancellous cementless lubeck total hip arthroplasty. Five-to-nine-year results. J Bone Joint Surg (Br). 1998;80:404-10.

39. Tensi HM, Ascherl R, Gese H, Hausler K. Material related aspects of surface structured endoprostheses. Biomed Tech (Berl). 1989;34:308-14

40. Cierny, G., 3rd, Mader, J.T. \& Penninck, J.J. A clinical staging system for adult osteomyelitis. Clin Orthop Relat Res, 7-24 (2003).

41. Schmidt $H G$, et al. Classification of haematogenous and post-traumatic osteomyelitis. Z Orthop Unfall. 2014;152:334-42.

42. Illgner U, Krenn V, Osada N, Bause L. Histopathology and microbiology of joint infections: extension of diagnostic safety in patients with chronic polyarthritis. Z Rheumatol. 2013;72:709-13.

43. Lengsfeld $M$, et al. Validation data for periprosthetic bone remodelling theories. J Biomech. 2002;35:1553-64.

44. Kaji H. Interaction between muscle and bone. J Bone Metab. 2014;21:29-40.

45. N Ozada, SG Yazdi, A Khandan, M Karimzadeh. A brief review of reverse shoulder prosthesis: arthroplasty, complications, revisions, and development. Trauma Monthly 23(2018).

\section{Publisher's Note}

Springer Nature remains neutral with regard to jurisdictional claims in published maps and institutional affiliations.
Ready to submit your research? Choose BMC and benefit from:

- fast, convenient online submission

- thorough peer review by experienced researchers in your field

- rapid publication on acceptance

- support for research data, including large and complex data types

- gold Open Access which fosters wider collaboration and increased citations

- maximum visibility for your research: over $100 \mathrm{M}$ website views per year

At BMC, research is always in progress.

Learn more biomedcentral.com/submissions 